Rakenteiden Mekaniikka (Journal of Structural Mechanics)

Vol. 53, No. 1, 2020, pp. 12-19

http://rakenteidenmekaniikka.journal.fi/index

https://doi.org/10.23998/rm.76266

(C) 2019 The Authors

Open access under license CC BY 4.0

\title{
Avoiding the high friction peak in fretting contact
}

\author{
Janne Juoksukangas ${ }^{1}$, Jouko Hintikka, Arto Lehtovaara, Antti Mäntylä, Joona Vaara and
} Tero Frondelius

Summary. Fretting fatigue and wear may exist if two parts have small amplitude relative rubbing between the contacting surfaces. A peak in the coefficient of friction typically occurs during the first thousands of loading cycles in dry fretting contact with quenched and tempered steel. This peak is related to adhesive friction and wear causing non-Coulomb friction and high local contact stresses possibly leading to cracking. The focus of the study is the effect of different experimental methods on the frictional behavior of the fretting contact between the steel surfaces. The use of pre-corroded specimens and contact lubrication delayed and reduced the initial peak. However, a pre-added third body layer removed the peak completely.

Key words: fretting, friction, fretting fatigue, fretting wear

Received: 31 October 2018. Accepted: 30 December 2019. Published online: 13 March 2020.

\section{Introduction}

Small amplitude rubbing between surfaces in contact can lead to fretting fatigue and wear, which can further cause catastrophic failure in machine components. The amplitude of slip is typically from a few micrometers to some hundreds of micrometers, leading to surface degradation and wear. The coefficient of friction (COF) in fretting contacts is typically high, even close to unity [11], basically regardless of the material pair in contact. In quenched and tempered steel, measured long-term value for COF is about 0.8 [8]. However, COF can peak at the beginning of tests having values of about 1.4 [8]. Due to high COF, tangential tractions and stresses can be high promoting fatigue crack nucleation. Fretting fatigue may occur at nominal stress levels below plain fatigue limit [4]. Both experimental and numerical research are utilized to study fretting. Nowadays, already component level simulations [12] are carried out using comprehensive and detailed models [13].

The initial peak in COF is related to adhesive friction and wear causing nonCoulomb friction [6]. This behavior is shown in Figure 1. The tangential force-relative

\footnotetext{
${ }^{1}$ Corresponding author: janne.juoksukangas@tuni.fi
} 

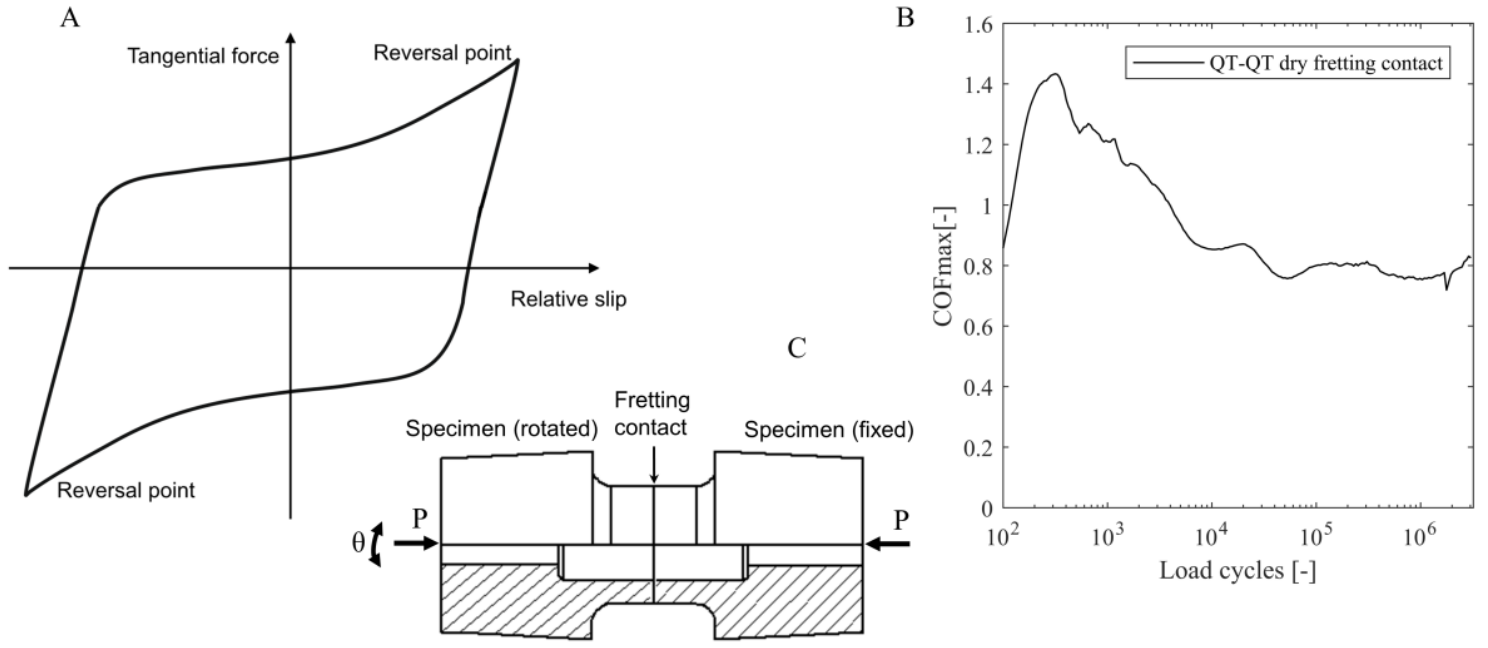

Figure 1. Schematic view of a fretting loop over one loading cycle (A), typical measured coefficient of friction $\left(\mathrm{COF}_{\max }\right)$ over one fretting test using dry quenched and tempered steel specimens (B) and the used test contact configuration (C).

slip graph presents a so-called 'fretting loop' during one loading cycle in gross sliding conditions, i.e., where the whole nominal contact area is experiencing slip. The tangential force clearly increases as the reversal points are approached (Figure 1A). This is labelled as non-Coulomb friction [9; 15], as in ideal Coulomb friction conditions tangential force would stay constant during the sliding part. The area inside the loop is the energy dissipated by friction. The coefficient of friction can be calculated from this energy (average $\mathrm{COF}$ ) or from the tangential force amplitude $\left(\mathrm{COF}_{\max }\right.$, maximum $\mathrm{COF}$ ) [8]. A typical COF behavior of a dry fretting contact using the quenched and tempered steel in gross sliding conditions is shown in Figure 1B. The COF peaks at the beginning $\left(\mathrm{COF}_{\max } \sim 1.4\right)$ and then levels off $\left(\mathrm{COF}_{\max } \sim 0.8\right)$ during some ten thousands of loading cycles. Figure 1C shows the used test configuration, having two annular specimens pressed together. In the course of loading, fretting debris is created and a part of it is entrapped in the contact, which changes wear behavior towards abrasive wear and decreases COF due to the velocity accommodation mechanism. A part of the debris is ejected from the contact, which is seen in the case of steels as red-brown oxidized powder.

Material degradation [16] and nucleation of cracks [10] have already been observed at loading cycles within the initial friction peak. Those cracks can further propagate causing complete fracture. Thus, studying factors affecting COF has a deep interest. In general, dozens of factors affecting fretting can be listed [2] and the frictional behavior of fretting contacts may be affected in several ways. Already, by running fretting tests below the fully developed friction load, the friction peak can be avoided [7]. Friction may be affected tribologically by applying a lubricant, for example. The use of a grease in fretting contact may notably decrease COF [3] and greases have also the ability to prevent the oxidation process [14]. The generation of fretting debris (third body layer) in the contact may affect COF and wear behavior [1]. Previous experiments using the same quenched and tempered steel in dry contact conditions have revealed that the third body layer can notably decrease wear rate, but COF behavior was unaffected [5]. COF 
has been measured to decrease [17] and the wear mechanisms have been affected in corrosive conditions [18].

This study experimentally investigated the effect of different experimental methods on the frictional behavior of quenched and tempered steel fretting contact. Both contacting parts were made of 34CrNiMo6+QT. Quenched and tempered steels are commonly used in heavy loaded machine elements. The fretting contact was lubricated with grease, pre-corroded specimens were used and a third body layer was applied to the contact before testing. These were compared to previous results using the same materials in dry contact conditions [8]. A large nominal contact area $\left(314 \mathrm{~mm}^{2}\right)$ with relatively low nominal normal pressure was used that may appropriately emulate contacts in practice.

\section{Experiments}

A fretting test device with a large annular flat-on-flat contact was used in the experiments. The test device is described comprehensively in [8]. Two identical specimens are pressed together (Figure 1C) and rotating movement in a back and forth manner is applied to one of the specimens around its central axis with rotation amplitude $\theta$. The second specimen is fixed. Thus, slip and fretting is created between the specimens. Due to the specimen geometry, the normal and tangential traction distributions are quite even. The normal load $P$ applied is kept constant during tests and the sliding amplitude at the contact interface is determined accurately from the measurements. Assuming Coulomb friction conditions, $\mathrm{COF}_{\max }$ can be calculated from the measured frictional torque and normal pressure distribution [8].

Three separate experimental methods were applied to study the frictional behavior of the quenched and tempered steel contact in gross sliding fretting conditions: (i) the contact was lubricated with grease, (ii) pre-corroded specimens were used and (iii) third body layer was added before testing. In the series with grease (i), a NLGI class 2 graphite grease with EP additives was applied once before the contact was closed and normal load applied. An excessive amount of grease was used so that the whole contact interface was surrounded by it. In the pre-corroded tests (ii), specimens were corroded for several hours using sodium hypochlorite $(\mathrm{NaClO})$ before testing. Only one of the specimens in the contact pair was pre-corroded and the second specimen had the pure ground steel surface. In the third body tests (iii), fretting debris (hematite) from previous fretting tests with the same material pair in dry contact conditions was added to the contact using debris-ethanol mix. The tests were started after ethanol was evaporated. Also in this case, debris was only added once (before testing). Otherwise, the basic test procedure [8] was followed in all series. The tests were carried out in typical laboratory environment conditions. The nominal normal pressure and sliding amplitude were $30 \mathrm{MPa}$ and $35 \mu \mathrm{m}$, respectively. The test duration was $3 \times 10^{6}$ loading cycles. The loading frequency was $40 \mathrm{~Hz}$ and the rotation amplitude was ramped up during the first 400 loading cycles. The average of the surface roughness $(\mathrm{Sa})$ values of the plain ground specimens was $0.24 \mu \mathrm{m}$. The normal pressure distribution in each test was adjusted at the beginning of testing using a pressure film. Two tests in each three series were carried out. 


\section{Results and discussion}

The COF curves of the three test series are shown in Figure 2. In addition, the results of previously made gross sliding tests [8] with the same material in dry contact conditions are shown as a reference. Compared to the dry contact conditions, the use of grease clearly decreases the friction peak to somewhat below 1.2. In addition, the peak is 'delayed', meaning that it occurs some hundreds of loading cycles later than in dry contact conditions. The delay may be related to strong initial presence of grease and its lubricating effect, while the disappearance (at least partly) of it leads to an increase in friction. It can be speculated whether regularly added grease would keep COF at low levels continuously. The use of pre-corroded specimens decreased the initial friction peak even more, close to unity. In addition, the delay was even longer. However, the initial friction peak was absent when the third body layer was added. This indicates that adhesive wear is diminished as direct metal-to-metal contact is at least partly prevented. In the grease series, the COF is very low during the very first loading cycles compared to other series, which may indicate good initial lubrication. What is common to all series, the stabilized, i.e. long-term $\mathrm{COF}$ value remains practically the same, slightly below the values in dry (reference) contact.

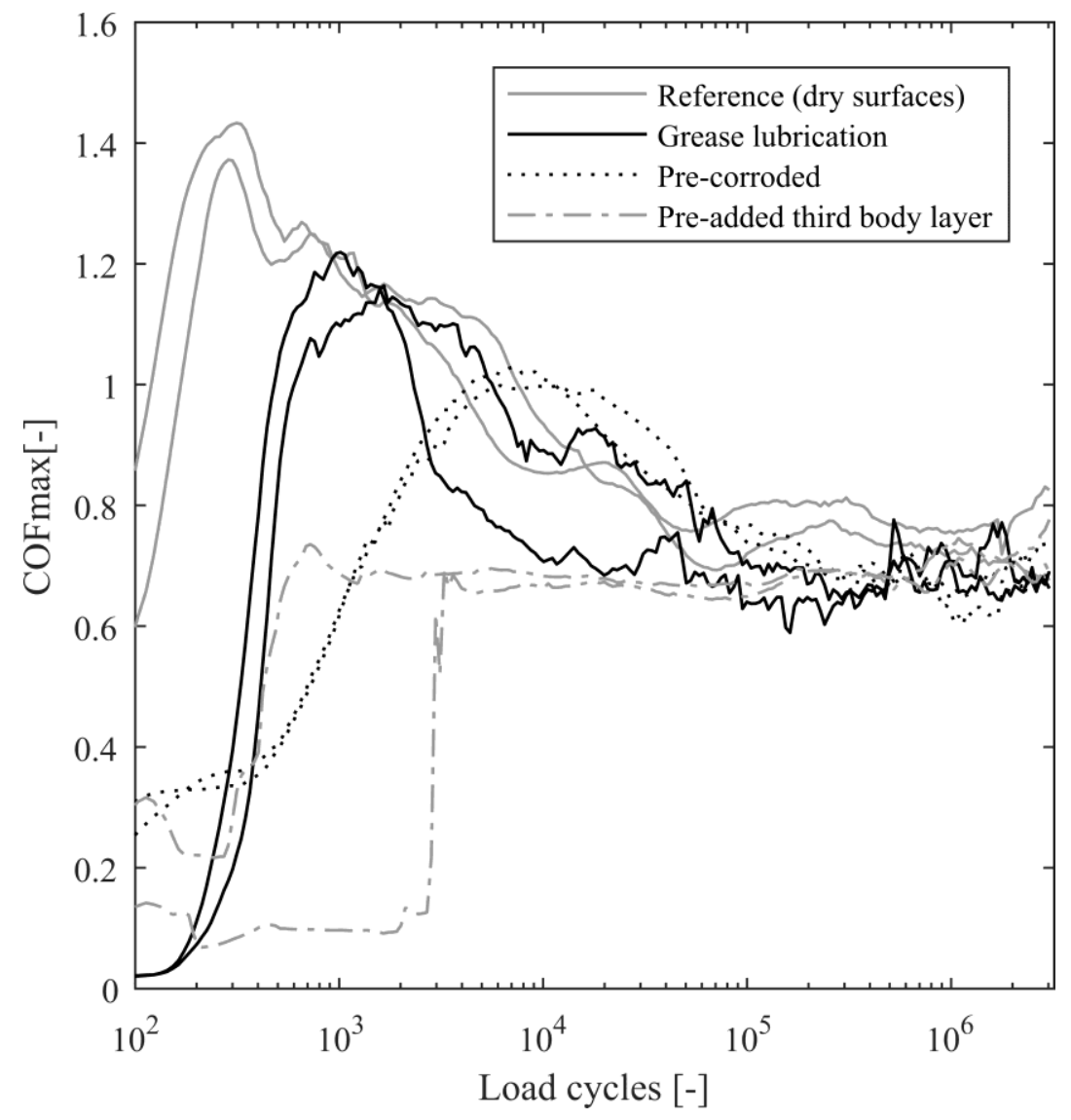

Figure 2. Coefficient of friction $\left(\mathrm{COF}_{\max }\right)$ during testing of all series. 
The fretting scars of contact surfaces are shown in Figure 3. Fretting damage is observed in every test. The greased specimen shows limited oxidation, which may be caused by the grease's 'sealing' effect. Areas of severe fretting damage, 'spots', can be observed in all series. However, smoother areas can be seen in all three series compared to the reference series. The change in color from reddish brown to metallic gray indicates changes in the composition of oxides. Similar characteristics in fretting scars between series support the similar steady-state COF behaviors observed between
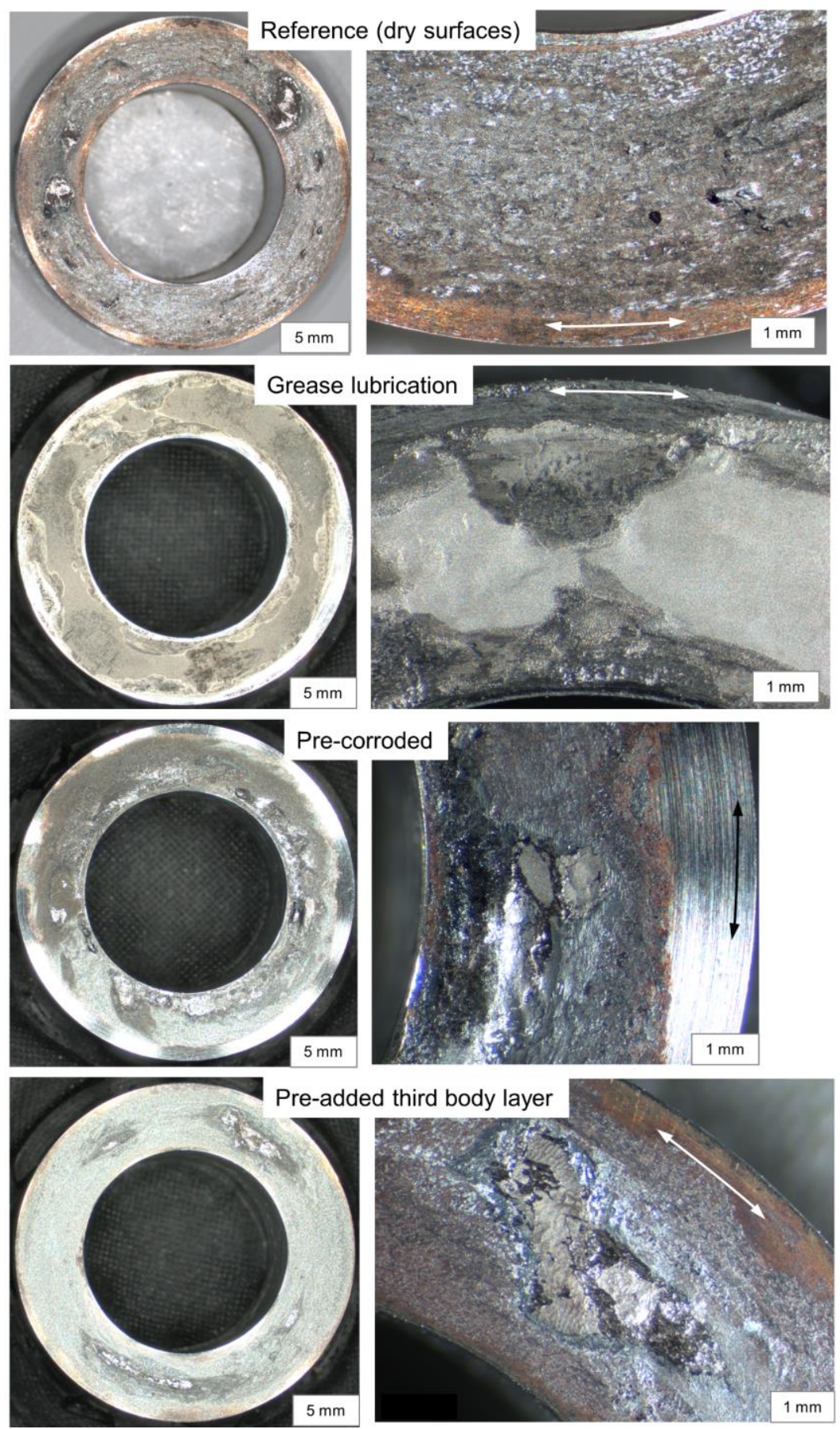

Figure 3. Fretting scars on contact surfaces. The arrows indicate the sliding direction. 
the tests (Figure 2). However, the scars convey the result of the whole evolution of fretting damage. Therefore, the effect of different phases, such as friction peak, on the fretting scar remains unknown. Table 1 lists the mass losses of the specimens in different series. The mass losses of the un-corroded countersurface specimens are listed in the Pre-corroded series.

The use of lubricant somewhat increased wear as the mass loss was increased $66 \%$ in comparison to the reference series value (Table 1). This is somewhat unexpected behavior, as COF decreased when using the grease. However, the difference in mass unit is rather low and more tests would be needed to validate this. Highest wear was measured with pre-corroded specimens. Predictably, the addition of the third body layer led to reduction in wear. However, even though wear was decreased and the initial friction peak avoided, severe fretting damage including adhesion spots were observed. Further studies, with repeat tests to gain statistically more reliable results, are needed to investigate this behavior.

Table 1. Mass losses of the specimens in each test.

\begin{tabular}{lccc}
\hline \multicolumn{1}{c}{ Series } & Mass loss [mg] & Avg mass loss [mg] & Difference to reference \\
\hline Reference (dry surfaces) & $7.47,4.12$ & 5.80 & \\
Grease lubrication & $10.15,9.05$ & 9.60 & $+66 \%$ \\
Pre-corroded & $11.77,26.33$ & 19.05 & $+229 \%$ \\
Pre-added third body layer & $2.14,4.56$ & 3.35 & $-42 \%$ \\
\hline
\end{tabular}

\section{Conclusions}

The effect of grease lubrication, pre-corrosion and the pre-added third body layer on the frictional behavior of a large fretting contact were studied using quenched and tempered steel.

- By using grease or pre-corroded specimens, it was possible to reduce and 'delay' the initial friction peak typically observed in dry quenched and tempered steel contact.

- By using the pre-added third body layer, it was possible to diminish the friction peak. Minimum wear was measured in this series.

- Long-term, stabilized, COF was practically unaffected in all series.

- However, severe fretting damage in terms of fretting scars including adhesion spots were observed in all series.

\section{Acknowledgements}

The authors are grateful for the financial support provided by Business Finland Oy (former Tekes) in the form of research projects ISA (Dnro 7204/31/2018), MaNuMiES (Dnro 3361/31/2015) and WIMMA (Dnro 1566/31/2015) and Wärtsilä Finland Oy, Agco Power Oy and Global Boiler Works Oy. 


\section{References}

[1] Y. Berthier, L. Vincent, and M. Godet. Velocity accommodation in fretting. Wear, 125(1-2):25-38, 1988. https://doi.org/10.1016/0043-1648(88)90191-3

[2] J. M. Dobromirski. Variables of Fretting Process: Are There 50 of Them? In M. H. Attia \& R. B. Waterhouse (Eds.), Standardization of Fretting Fatigue Test Methods and Equipment, ASTM STP 1159 (pp. 60-66). Philadelphia: American Society for Testing and Materials, 1992.

[3] L. Haviez, S. Fouvry, R. Toscano, and G. Yantio. An energy-based approach to understand the effect of fretting displacement amplitude on grease-lubricated interface. Wear, 338-339:422-429, 2015. https://doi.org/10.1016/j.wear.2015.07.015

[4] D. A. Hills and D. Nowell. Mechanics of Fretting Fatigue. Dordrecht: Kluwer Academic Publishers, 1994.

[5] J. Hintikka, A. Lehtovaara, and A. Mäntylä. Third Particle Ejection Effects on Wear with Quenched and Tempered Steel Fretting Contact. Tribology Transactions, 60(1):70-78, 2017. https://doi.org/10.1080/10402004.2016.1146813

[6] J. Hintikka, J. Juoksukangas, A. Lehtovaara, T. Frondelius, and A. Mäntylä. Nonidealities in fretting contacts. Journal of Structural Mechanics, 50(3):171-174, 2017. https://doi.org/10.23998/rm.64886

[7] J. Hintikka, A. Lehtovaara, T. Frondelius, and A. Mäntylä. Tangential traction instability in fretting contact below fully developed friction load. Journal of Structural Mechanics, 50(3):175-178, 2017. https://doi.org/10.23998/rm.65105

[8] J. Hintikka, A. Lehtovaara, and A. Mäntylä. Fretting-induced friction and wear in large flat-on-flat contact with quenched and tempered steel. Tribology International, 92:191-202, 2015. https://doi.org/10.1016/j.triboint.2015.06.008

[9] J. Hintikka, A. Lehtovaara, and A. Mäntylä. Normal displacements in nonCoulomb friction conditions during fretting. Tribology International, 94:633-639, 2016. https://doi.org/10.1016/j.triboint.2015.10.029

[10] J. Juoksukangas, V. Nurmi, J. Hintikka, M. Vippola, A. Lehtovaara, A. Mäntylä, J. Vaara and T. Frondelius. Characterization of cracks formed in large flat-on-flat fretting contact. International Journal of Fatigue, 124:361-370, 2019. https://doi.org/10.1016/j.ijfatigue.2019.03.004

[11] K. J. Kubiak, T. W. Liskiewicz, and T. G. Mathia. Surface morphology in engineering applications : Influence of roughness on sliding and wear in dry fretting. Tribology International, 44(11):1427-1432, 2011. https://doi.org/10.1016/j.triboint.2011.04.020

[12] A. Mäntylä, J. Göös, A. Leppänen, and T. Frondelius. Large bore engine connecting rod fretting analysis. Journal of Structural Mechanics, 50(3):239-243, 2017. https://doi.org/10.23998/rm.64914

[13] A. Mäntylä, J. Juoksukangas, J. Hintikka, T. Frondelius, and A. Lehtovaara. FEM-Based Wear Simulation for Fretting Contacts. Journal of Structural Mechanics, 53(1), 20-27, 2020. https://doi.org/10.23998/rm.76261

[14] I. R. McColl, R. B. Waterhouse, S. J. Harris, and M. Tsujikawa. Lubricated fretting wear of a high-strength eutectoid steel rope wire. Wear, 185(1-2):203212, 1995. https://doi.org/10.1016/0043-1648(95)06616-0

[15] D. M. Mulvihill, M. E. Kartal, A. V. Olver, D. Nowell, and D. A. Hills. Investigation of non-Coulomb friction behaviour in reciprocating sliding. Wear, 271(5-6):802-816, 2011. https://doi.org/10.1016/j.wear.2011.03.014

[16] V. Nurmi, J. Hintikka, J. Juoksukangas, M. Honkanen, M. Vippola, A. Lehtovaara, A. Mäntylä, J. Vaara and T. Frondelius. The formation and characterization of fretting-induced degradation layers using quenched and 
tempered steel. Tribology International, 131:258-267, 2018.

https://doi.org/10.1016/j.triboint.2018.09.012

[17] V. Périer, L. Dieng, L. Gaillet, C. Tessier, and S. Fouvry. Fretting-fatigue behaviour of bridge engineering cables in a solution of sodium chloride. Wear, 267(1-4):308-314, 2009. https://doi.org/10.1016/j.wear.2008.12.107

[18] P. Zhang, X. Liu, W. Lu, W. Zhai, M. Zhou, and J. Wang. Fretting wear behavior of $\mathrm{CuNiAl}$ against $42 \mathrm{CrMo} 4$ under different lubrication conditions. Tribology International, 117:59-67, 2018. https://doi.org/10.1016/j.triboint.2017.08.013

Janne Juoksukangas, Arto Lehtovaara, Jouko Hintikka (formerly)

Tribology and Machine Elements, Materials Science and Environmental Engineering, Faculty of Engineering and Natural Sciences, Tampere University

P.O. Box 589, FI-33014 Tampere University, Finland

janne.juoksukangas@tuni.fi, arto.lehtovaara@tuni.fi

Jouko Hintikka, Antti Mäntylä, Joona Vaara, Tero Frondelius

R\&D and Engineering

Wärtsilä

P.O. Box 244, 65101 Vaasa, Finland

jouko.hintikka@wartsila.com, antti.mantyla@wartsila.com, joona.vaara@wartsila.com, tero.frondelius@wartsila.com

Tero Frondelius

University of Oulu

Pentti Kaiteran katu 1

90014 Oulu, Finland

tero.frondelius@oulu.fi 